\title{
Bioethics of the refusal of blood by Jehovah's Witnesses: part 2. A novel approach based on rational non-interventional paternalism
}

\author{
Osamu Muramoto Kaiser Permanente Northwest Division, and Northwest Permanente PC, Oregon, USA
}

\begin{abstract}
Most physicians dealing with fehovah's Witnesses $(\mathcal{F W s})$ who refuse blood-based treatment are uncertain as to any obligation to educate patients where it concerns the $\mathcal{F W}$ blood doctrine itself. They often feel they must unquestioningly comply when demands are framed as religiously based. Recent discussion by dissidents and reformers of morally questionable policies by the $\mathcal{F W}$ organisation raise ethical dilemmas about "passive" support of this doctrine by some concerned physicians. In this paper, Part 2, I propose that physicians discuss the misinformation and irrationality behind the blood doctrine with the $\mathcal{Y W}$ patient by raising questions that provide new perspectives. A meeting should be held non-coercively and in strict confidence, and the patient's decision after the meeting should be fully honoured (non-interventional). A rational deliberation based on new information and a new perspective would enable a certain segment of $\mathcal{F W}$ patients to make truly informed, autonomous and rational decisions.
\end{abstract}

(Fournal of Medical Ethics 1998;24:295-301)

Keywords: Religion; Jehovah's Witnesses; blood transfusion; medical ethics; physician-patient relations; informed consent

\section{Introduction}

In the companion paper, Part $1,{ }^{1}$ I suggested that physicians faced with ethical dilemmas related to treating Jehovah's Witness (hereafter "JWs") patients who refuse blood products should consider, not only the official position of the controlling religious organisation (Watch Tower Bible and Tract Society, hereafter "WTS"), but also dissident and reform views on the doctrine of blood refusal. A growing body of evidence from current and former members, supported by WTS publications, suggests that unethical practices, such as breaching JW patients' confidentiality, are encouraged. According to dissidents the doctrine is based on inconsistent and contradictory teachings and policies, and Jehovah's Witnesses are given misinformation and steered away from cor- rect information and rational reasoning. Unless only marginally associated, they are well aware of the consequences of not holding to organisational policies and that their privacy is subject to invasion. It is likely that principles of patient autonomy and informed consent (or refusal) are compromised. The critical perspectives of dissidents and reformers suggest that the medical community's supportive attitude towards the blood doctrine should be reconsidered.

Recently, Savulescu ${ }^{2}$ questioned the attitude of physicians who accept patients' decisions without making their own moral judgments. He proposed the notion of "rational non-interventional paternalism" which recommends that physicians form conceptions of what is best for their patients and argue rationally with them. This approach to ethical decisions retains the old-style paternalist's commitment to deciding what is, all things considered, best for the patient, but rejects compelling the patient to adopt that course. More recently, Savulescu and Momeyer ${ }^{3}$ argued that informed consent should be based on rational beliefs. They used the case of JW' refusal of blood transfusions as an example of choice based on irrational beliefs. They further argued that if physicians are to respect patient autonomy and help patients choose and act rationally, they must not only provide information but should care about the theoretical rationality of their patients. They proposed that physicians act as "critical educators" and concluded that a physician's failure so to act would ultimately be viewed as abandoning patients to "autonomy-destroying theoretical irrationality".

In this paper I will expand on this argument and propose that medical professionals familiarise themselves with the inherent flaws of the blood doctrine, and provide $\mathrm{JW}$ patients with new perspectives and rational reasoning by posing a few simple questions which can be presented in "non-interventional" fashion and without outside pressure. These questions may enable patients to view their doctrine from new perspectives and 
give them a chance to make a more informed, autonomous and rational decision.

\section{Ethical dilemmas}

Jehovah's Witness patients who refuse life-saving blood transfusions may not only be irrational, as Savulescu and Momeyer ${ }^{3}$ argue, but may also be misinformed, misguided and, to some degree, coerced, according to the information, based on direct knowledge and experience, provided by dissidents and reformers. Knowing the basis for the blood doctrine and how it is enforced, physicians face this question: should we ignore this information and respect the patient's decision no matter how irrational and misguided we think he/she might be, or should we pursue in-depth discussion to encourage a rational and truly autonomous decision? I argue that the latter course should be taken so far as circumstances permit. Physicians may not be in the position of judging the validity of religious doctrine in an ultimate sense, but they should still examine the rationality and morality of decisions their patients make. I will first discuss reasons why physicians should explore further.

\section{ARE JWS TRULY “INFORMED"?}

It is established practice to discuss procedures and treatments with patients and disclose all benefits, risks and alternatives in order to obtain an informed consent. It is uncommon to discuss the basis for a patient's decision, out of a desire not to infringe upon patient autonomy and privacy, or as in this case, religious freedom. The question I present here is whether we should leave the patient's decision unchallenged if there is evidence that it is based on misinformation or informationcontrol enforced by covert or, in some cases, overt coercion.

DO JWS TRULY HAVE "AUTONOMY"?

Do JWs have true autonomy in making decisions? There is considerable documentation that JWs can be subject to psychological coercion, as shown in Part 1. If we suspect that a patient may be under such coercive persuasion, should we ignore this possibility and simply comply with his or her request? I argue that such an attitude borders on patient abandonment under the guise of pseudoautonomy.

DOES CONSULTATION WITH CHURCH (WTS) OFFICIALS PROMOTE PATIENT AUTONOMY?

It is common for JWs and treating physicians to consult with church officials and members of their hospital liaison committee for guidance on the blood doctrine, as to what is prohibited and what is allowed. Such consultation is recommended $\mathbf{F} y$ well-established guidelines for blood transfusiơf ${ }^{4}{ }^{4}$ By obtaining such help can the physician becomie biased in favour of the doctrine and make ffis decision based more on WTS policy than protegction of the patient's health and life? How can sulh consultation promote patient autonomy when organisational rules make the position of the committee non-negotiable, so that the patient must always refuse blood and the physician must alwæis treat without blood?

The decisions of a physician which is based solely on information provided by the chum becomes ethically questionable when there 尺re serious questions about the ethics of the church itself. In many reported cases the elders of church organisation applied pressure to a pationt to conform to its blood policy, often caus reversal of an earlier patient decision..$^{5-9}$ Can we take the patient's decision after consultation whth such an "advisor" as being autonomous, given the information-control and coercive practices of this religion?

\section{CAN RATIONAL DELIBERATION CHANGE A PATIE 8 VIEW?}

There are anecdotal reports of individuals made confused decisions and changed their minids after discussion with medical professionals. ${ }^{6} \phi^{12}$ Not all persons who belong to a religious organisation conform to its doctrines. If JWs always acted identically, their wishes, beliefs and answers would all be known from doctrines and official publioations, and there would be no need for deliberation. Yet many decisions made by physicians caring for JW patients are simply cut-and-dried. M\$st physicians spend little time inquiring about the patient's decision and the circumstances unger which he made it. However, individuals vary in commitment to and interpretation of WTS polky. Certain treatments may be acceptable to one $\mathrm{fW}$ but not to another. ${ }^{1314}$ Some JWs may show ambivalence or even willingness to be forcedfoto receive blood-based treatment as long as it is officially noted as contrary to their wishes. ${ }^{15}$ Some JWs are willing to receive blood under the congition of complete confidentiality. ${ }^{16}$ Such cases show that failure to explore individual JWs' views r cause physicians to let JWs die unjustifiakly, whereas rational deliberation on an individoal basis can save lives.

CAN IRREVOCABLE LOSS OF LIFE BE JUSTIFIED, BAS货D ON THE INCONSTANT DOCTRINAL SYSTEM OF JWS Although the basic blood doctrine has been in place for 40 years, details have undergone many 
modifications, as shown in Part 1. There have been several doctrinal reversals on life-saving medical treatments such as organ transplants, vaccination and allowance of certain blood components. Should physicians ignore this potentially unstable ground and stand idly by while a patient dies?

\section{PHYSICIANS MAY INADVERTENTLY PROMOTE}

IRRATIONALITY AND UNETHICAL PRACTICES BY GIVING UNQUESTIONING SUPPORT TO JW PATIENTS' DECISIONS

Respecting patients' decisions and supporting their beliefs when these manifest inconsistent reasoning are two different things. By cooperating with a JW's request for heroic effort, do "sympathetic doctors" inadvertently advance the church's cause, which may involve practices morally repugnant to most physicians? Physicians tend to confine themselves to a narrow role, staying within the framework of patient autonomy and religious freedom. However, this passivity or onesided effort to accommodate "no-blood" treatment, has further "standardised" the treatment of JWs with little regard for the ethical question of the patient's decision-making process.

Some physicians feel that the some of the expensive alternative, intense and hightechnological treatments could be allocated more efficiently. ${ }^{1718}$ For them, allocation of limited health care resources is as important an ethical principle as are autonomy and religious freedom.

\section{A suggested approach to JW patients based on rational non-interventional paternalism}

To lessen the ethical dilemmas, I suggest an approach using principles of rational noninterventional paternalism. ${ }^{2}$ Before discussing this approach I should emphasise that this type of ethical deliberation is necessary only when there is no reasonable alternative to blood-based treatment, or when so-called "no-blood" treatment would incur significantly higher risk and cost.

\section{EMERGENCY CASES}

For obvious reasons the deliberative approach cannot be used in emergencies. In these cases automatic acceptance of printed instructions on the so-called "blood card" most JWs carry is potentially dangerous and may violate the rights of JWs who are ambivalent or who have recently changed their belief. There are anecdotal cases of invalid "blood cards", which are used as a form of advance directive. Particularly important is the card's date. A card with no date or an old date should not be automatically accepted since former members and current members who are considering leaving the organisation may carry outdated cards. Some JWs are under extreme pressure to carry a card even though they disagree with the policy. A former JW might continue to carry a blood card for the sake of peace with a JW spouse, considering the strife it would cause if the believing mate discovered the true views of the dissident mate.

On the other hand, emergency conditions do not allow physicians to verify "blood card" status or discuss the patient's conviction. It is this author's opinion that if there is any doubt about the patient's wishes the physician should first take whatever steps are necessary to stabilize and remove the patient from immediate danger of death or severe disability until a court ruling or other independent assessment of the applicability of the card can be obtained. This view is also supported by others. ${ }^{12}{ }^{19}{ }^{20}$ In a Canadian court case, a doctor was found guilty of battery when he treated with blood transfusions an emergency patient who carried an undated and unwitnessed card. ${ }^{21}$ This ruling was criticised by the medical community in Canada. ${ }^{22-24}$

In the United States, ${ }^{25}$ the validity of a "blood card" was discounted in the case of an incompetent patient. In another the court ordered a transfusion for a comatose patient despite the card. ${ }^{12}$ Similar court rulings involving incompetent JW patients under emergency conditions have been reported. ${ }^{26}$ Despite assurance from WTS officials that a physician is absolved from legal and ethical responsibility for withholding blood transfusions, wrongful death suits were brought against physicians by the families of JWs who died after they refused blood transfusions. ${ }^{25}{ }^{27}$ One may view this situation from the perspective that if we can be sued either for treating or not treating with blood, we would rather it be for saving the patient's life.

\section{STABLE CASES}

In the case of stable patients requiring elective transfusions, I propose that each physician first validate the patient's status as a JW. In one case a woman was presented as "a fervent JW" by her JW mother ${ }^{28}$ but her status was later officially denied by the WTS. ${ }^{29}$ This shows that we have reason not to accept at face value the word of anyone other than the patient regarding his or her status as a JW, particularly family and friends. After the status is confirmed with a competent patient, I propose that each physician have a confidential meeting with the patient about informed refusal of blood products. A most important condition of this discussion would be an atmosphere in which the 
patient could feel free from influence by church officials or peers, including family members. Just as the physician does not intervene in a family and church-based discussion, so it is important that the physician himself be able to speak with the patient without influence by others.

As mentioned before, a number of case reports exist in which a patient's initial decision was reversed to conform to WTS policy after church officials visited the patient. Therefore, it is recommended that consultation with church officials be made only when requested by the patient, and only when he is free from outside pressure and has normal mental status. The consultation should be limited to the information needed for immediate patient care. Otherwise, such consultation would complicate the doctor-patient relationship and invade the privacy of doctor-patient decision making, allowing further outside intervention. A private meeting between only the physician and the patient is preferred.

In this meeting the prognosis of each scenario should be explicitly discussed. This should include not only the possibility of death, but prolonged disability and suffering along with a burden on the family and society. The WTS has repeatedly emphasised that death due to lack of blood transfusions is nothing compared to the eternal life they can obtain by refusing blood. But JWs have given little consideration to the prolonged suffering and disability that can result.

\section{QUESTIONS THAT MAY BE ASKED}

The physician can then ask several questions about the basis for the refusal of blood. If the physician is versed with the appropriate Bible passages, he may discuss the difficulties with WTS Bible interpretation. Although JWs may be generally prepared to answer a few common questions, they invariably are unaware of the fundamental contradictions as pointed out in Part 1. Physicians who are not interested in Bible discussion may still pose many questions regarding the irrationalities of the doctrine. The following three points give examples that might be presented to the patient in a non-coercive fashion. A small brochure has been prepared to assist physicians and could be used in this session. ${ }^{30}$

Since initiating such an approach may come across to the JW patient as a frontal assault on his belief system, it would be appropriate to preface the discussion with some introductory remarks, such as:

"I respect sincerely your concern for conscience and your desire to do what is right according to your belief. And I hope you will believe me when I say that I am also guided by my conscience andira concern to do what is right based on what:-I believe. There are certain things that are worth dying for. At the same time I want to feel assurzd that a patient has considered matters with fill information and is satisfied that his or her decision has a solid and stable foundation. It would hefip me feel more free from concern in my effort $\$$ preserve your health if I could hear your thoughts on certain points that, at least to me, seem difficult to reconcile."

Then the following questions may be introduct

1. "I am concerned by my knowledge that the have been a number of significant changes Tn related understandings by the WTS. Probaby you know that vaccination and organ trangs plants were for some time ruled unacceptabfe and morally wrong. These are now considered acceptable. But I think you would agree that the previous rulings may have had some qu贯e serious effects - illness, disability, even deat离while they were in force. It would seem tha的a person would want to consider what the future might yet bring in further changes of vieypoint. If holding to some present policy wease to result in disability or even death in your case, and that policy were reversed next ye some years from now, do you feel that such lass would have been worthwhile and justified.0 I understand these changes are viewed as 'ne light' and I wonder if you have given a苗y thought to the possibility of 'new light' on any of the policies regarding blood?"

2. [The physician mentions different blood components and asks if the JW patient knows which are allowed and which are prohibited. Many would not know. The division of acce grtable and non-acceptable components coufd then be stated and then the physician ask "Could you clarify for me why immunogloberlins, albumin and clotting factors may Be accepted but plasma must not be accepted, when plasma is basically the combination Nf water plus those acceptable components? I I read the WTS explanation that 'abstainimg from blood means not taking it into our bodies at all'. Could you help me understand how it is that many components of blood are allowedf్fo be taken into the body, some of which requife the storing of very large amounts of blood to extract the specific blood components volved? Could you show me anything in the Bible that actually discusses such matters $\mathbb{Q} \mathrm{s}$ acceptance or non-acceptance of specific blo $\overline{\text { d }}$ components? Since this is not directly considered in the Bible, is it not a case of an organi- 
sational policy involved rather than actual biblical teaching? If that is so, and since there is certainly no scientific basis for such policy, have you considered the possibility that the component you are refusing now could later be determined by the WTS as acceptable, perhaps even in the near future?"

3. "I think you recognize that blood transfusions are nowhere specifically discussed in the Bible, although it does say we should abstain from eating blood. Do you think eating blood and blood transfusions are the same? Do you know what happens if you eat blood? It will be digested and broken down to small molecules and no longer function as blood. By contrast, if the blood is introduced into your blood stream, it will continue to function as blood and carry oxygen. Therefore, eating and transfusion have an entirely different effect on your body. Red blood cells are a type of organ that carries oxygen, and blood transfusions are a transplantation of this cellular organ into the blood stream. The transplanted blood cells function as blood cells, and are not digested and absorbed as nutrients. Therefore blood transfusion is a form of organ transplant. I understand the WTS considers organ transplants a matter of conscience and that they may be accepted, am I correct? If I told you that you should abstain from meat because you have a heart disease due to high cholesterol, do you think I would have meant to abstain from heart transplants? Just like the difference between eating and transplanting an organ, there is a complete difference in effect on your body between eating and transfusing blood."

Additional points of contradiction and irrationality may be discussed at the physician's discretion. Sample questions are presented in the appendix to this paper. In discussing those questions, I suggest the following three precautions be carefully heeded.

First, this discussion should be held when there is no imminent danger to the patient's life, and he or she is neither in any great distress nor has impaired mental status. Otherwise, the physician's attitude may be viewed by JWs as coercive and abusive of his authority.

Second, the patient should be assured from the outset that doctor-patient confidentiality will be strictly observed and whatever decision the patient makes in this meeting and thereafter will not be made known to the family or congregation members. Again, integrity with regard to basic principles of medical ethics and patient confidentiality is crucial because of the existence of medical personnel informants among JW peers, and the patient should be reassured that special care will be taken in his or her case.

Third, I suggest not debating any religious convictions, such as the nature of God, the doctrine of the end of the world, moral conduct and so forth, that are beyond what is necessary for the immediate treatment. The physician should keep uppermost in mind that these questions are to give the patient different perspectives from what he has been taught by the WTS, and to draw the patient into rational thinking with correct information.

Note the crucial difference between classic paternalism and this new approach of rational non-interventional paternalism. It is not the purpose of the meeting to win an argument with the patient, using the physician's authority. A peaceful and rational discussion, avoiding argument, followed by suggestion that the patient think about the questions before giving a final decision should be most effective. Then the final decision made by the patient must be fully respected.

\section{Discussion}

To my knowledge this is the first article in medical literature that addresses the need of physicians to understand and deal with the fundamental problems of the JW blood doctrine. Traditionally most physicians are uncertain of their obligation to educate patients about the doctrine itself, because such activity may be viewed as invading the patient's religious freedom. Physicians often feel that they must unquestionably comply when any demands or refusal of certain treatment from the patient is framed as religious.

Such "passive" support in the medical community, with little critical evaluation of the religious practice itself, has created in many parts of the world an atmosphere of automatically accepting the martyrish request of JW patients that physicians make heroic efforts, which may involve greater risks and costs. A physician's alternatives are to transfer patients to a "sympathetic doctor" or let them die due to lack of any other alternatives. In this and the companion paper, I suggest that physicians should reconsider the "status quo" of "passive support" by carefully evaluating dissident views and critical information, and thereby take a more active role by exploring patients' decision making in rational and intelligent discussion.

Some may argue that these questions make a value judgment of religious beliefs under the guise of medical discussion, and that this should be beyond the scope of the doctor-patient relationship. Another argument would be that posing those questions is manipulative towards the 
patient's religious faith. However, a WTS lawyer blamed physicians who transfused a JW patient for not exploring the patient's value system and religious conviction. ${ }^{31}$ This indicates that at least some JWs would welcome such discussion. The purpose of asking pointed questions is to separate out the JWs who might reconsider the doctrine once they are presented with viewpoints they had never considered. These are not questions of whether their faith itself is true or false; rather, they concern the facts and rationality on which the blood doctrine is supposed to be based.

\section{Hypothetical religion}

To illustrate the difference, consider a hypothetical religion whose leader is believed to be the reincarnation of Jesus. Questioning a member as to whether the leader is truly the reincarnation of Jesus would be a direct challenge to the faith itself; questioning if he knows the facts about the leader's immoral behavior which are not disclosed to the followers may give him new information. Continuing to believe the leader is the reincarnation of Jesus after learning of his immoral behavior is irrational, but still can be held as "truth" by some followers. Others may reevaluate their belief system in light of the new information, and abandon the irrationality.

Another argument would be that "no-blood" treatment is beneficial in most cases, and that the physician's focus on the blood doctrine may bias him away from such safer treatment. As stated previously, I do not suggest that this proposed approach is necessary when a "no-blood" option is readily available for the treatment of a particular JW patient, without significantly greater risks and costs. However, at the present time, there are still many medical and surgical conditions which can be treated only with blood products, or which can be treated without blood products but only with expensive, risky and high-technological interventions that put the patient, the physician and the hospital in jeopardy.

What would be accomplished by this type of discussion? Because it is non-interventional, the final outcome will be up to individual JW patients. In reality, I do not expect any significant number of JWs will easily change their stance after one or two private meetings with a physician. However, in view of emerging developments taking place in this religion, as more adherents are given a chance to review their religion objectively, I expect that some JWs will be impacted by this approach and will avoid unnecessary death and disability.

Aside from the lives saved by reevaluation of the blood doctrine, this approach will also fulfil the moral obligation of physicians, whose values should be as much respected as the patientsit. Savulescu ${ }^{2}$ argued that medicine should have commitment to some value. Automatic accefftance of religious policy that contradicts $\underset{\mathrm{c}}{\overrightarrow{\mathrm{a}}}$ physician's values, particularly if that policy is based on irrationality and unethical practices, should be challenged. Savulescu wrote that, whäfe attempting to convince a patient that he is wromg in choosing some course may threaten his autonomy, using rational argument will enable $e_{a}$ patient to act and choose more autonomously. . order to have rational discussion with a $\overrightarrow{\mathrm{CH}}$ patient, both the use of misinformation a n contradictions inherent in the blood doctrine ne]্ه to be presented and corrected. Provided with n\&w perspectives, the patient's choice will beconfife more spontaneous, and more an expression of his autonomy.

While this author uses the case of JW refusalof blood transfusions to propose an approach using rational non-interventional paternalism, the sane approach can be applied to any authoritarian rejgious groups that control the information fis members receive, or coerce by intimidation and promote irrational beliefs and practices in mediø 1 care. These ethical dilemmas are not experie with members of more traditional religions. 值 rebuttal to articles that discussed a JW patient who did not make an autonomous decision, a fow physician stated that "adherents of all religions gेo not make free, autonomous decisions of coscience because of what their church teaches" 3 This generalisation ignores the fact that only those members of "high-control" religious groups, suơơh as the JWs, experience much intimidation and coercion to accept misinformation. While value patient autonomy regardless of religiogis affiliation, I propose that misinformation and coercion under the guise of pseudo-autonom should be challenged by each medical profêssional.

\section{Appendix}

The following additional questions can be usednin the private meeting with JW patients.

1. If storing your own blood for an autologoors transfusion is wrong, why does the WSS permit the use of various blood componexts that must be donated and stored before being used by JWs? Why can JWs accept those blood components and benefit from the blood that others donate, but will not donate blood the mselves? Would giving blood to help save otheis' lives, including the lives of your spirit迎 brothers and sisters (other JWs), be the loving and Christian thing to do? 
2. Have you ever seen the WTS publications discuss the fact that the only effective life-saving treatment for rapid and massive haemorrhage is emergency blood transfusions? [The answer should be no.] Why does the WTS need to keep such critical information from being made known to JWs, and why does it always emphasise the negative aspects of blood-based treatment?

3. I understand that JWs believe blood should not be eaten because it is sacred as it symbolizes life. Then could you help me understand how the symbol could be of greater value than the reality it symbolises? When there is a massive and rapid haemorrhage and blood transfusion is the only life-saving measure, is it a contradiction in itself to let a person die by placing more importance upon the symbol than the reality which it symbolises?

\section{Author's note}

At the proof stage, an important development in the blood policy of Jehovah's Witnesses was revealed in the Internet. In an agreement at the European Commission of Human Rights (http:// 194.250.50.201/eng/28626.28.html) between the Watch Tower Society and the government of Bulgaria, the society claimed that the members now "have free choice" to receive blood "without any control or sanction". As of July 1998, there is obvious confusion among the members; some view this as change in policy, whereas the society denies such. It is unclear how this denial could reconcile with the above public agreement.

Osamu Muramoto, MD, PhD, is a member of the ethics committee at Kaiser Permanente Northwest Division, and a Neurologist at Northwest PermanentePC, Portland, Oregon, USA. Address correspondence to: Kaiser East Interstate Medical Office, $3414 \mathrm{~N}$ Kaiser Center Drive, Portland, Oregon 97227, USA. E-mail: muramotosa@kpnw.org

\section{Disclaimer}

Views and opinions expressed herein are personal and do not reflect those of Kaiser Permanente and Northwest Permanente PC.

\section{References and notes}

1 Muramoto O. Bioethics of the refusal of blood by Jehovah's Witnesses: part 1. Should bioethical deliberation consider dissidents' views? Fournal of Medical Ethics 1998;24:223-230.

2 Savulescu J. Rational non-interventional paternalism: why doctors ought to make judgments of what is best for their patients. fournal of Medical Ethics 1995;21:327-31.

3 Savulescu J, Momeyer RW. Should informed consent be based on rational beliefs? Fournal of Medical Ethics 1997; 23:282-8.

4 Spence RK. Surgical red blood cell transfusion practice policies. The American fournal of Surgery 1995;170, 6A:3s-15s
5 Oneson R, Douglas DK, Mintz PD. Jehovah's Witnesses and autologous transfusion. Transfusion 1985;25:179.

6 Junkerman C. Jehovah's Witnesses and the refusal of blood. Fournal of Clinical Ethics 1990;1:167-8.

7 Mann MC, Votto J, Kambe J, McNamee MJ. Management of the severely anemic patient who refuses transfusion: lessons learned during the care of a Jehovah's Witness. Annals of Internal Medicine 1992;117:1042-48.

8 Lawry K, Slomka J, Goldfarb J. What went wrong: multiple perspectives on an adolescent's decision to refuse blood transfusions. Clinical Pediatrics 1996; 35: 317-21.

9 Rosen P [editorial]. Religious freedom and forced transfusion of Jehovah's Witness children. Fournal of Emergency Medicine 1996;14:241-3.

10 Granger C. Managing a Jehovah's Witness who agrees to blood transfusion. British Medical fournal 1994;309:612.

11 Kerstein MD. Discussion: transfusion guidelines for cardiovascular surgery: lessons learned from operations on Jehovah's Witnesses. Fournal of Vascular Surgery 1992;16:829.

12 Kleinman I. Written advance directives refusing blood transfusion: ethical and legal considerations. The American Fournal of Medicine 1994;96:563-7.

13 Findley LJ, Redstone PM. Blood transfusion in adult Jehovah's Witnesses. A case study of one congregation. Archives of Internal Medicine 1982;142:606-7.

14 Vanelli P, Castelli P, Condemi AM, Santoli C. Blood saving in Jehovah's Witnesses. Annals of Thoracic Surgery 1991;52:899900.

15 Davis P, Herbert M, Davies DP, Verrier Jones ER. Erythropoietin for anemia in a preterm Jehovah's Witness baby. Early Human Development 1992;28:282.

16 Odebiyi AI. Cultural influences and patient behavior: some experiences in the paediatric ward of a Nigerian hospital. Child Care, Health and Development 1984;10:54.

17 Collins CD. NHS trusts and Jehovah's witnesses. Lancet 1992; 339:1302.

18 Jederlinic PJ, Rockwell JC. Patient's choices and the medical commons. Annals of Internal Medicine 1992;119:170-1.

19 Layon AJ, D'Amico R, Caton D, Mollet CJ. And the patient chose: medical ethics and the case of the Jehovah's Witness. Anesthesiology 1990;73:1258-62.

20 Finfer S. Managing patients who refuse blood transfusions: an ethical dilemma. Author's view. British Medical fournal 1994;308:1425.

21 Brahams D. Jehovah's Witness transfused without consent: a Canadian case. Lancet 1989;2, 8676:1407-8.

22 Noble WH. CMPA and Jehovah's Witness. Canadian fournal of Anesthesia 1991;38:801-2.

23 Trent B. Jehovah's Witnesses and the transfusion debate: "We are not asking for the right to die". Canadian Medical Association fournal 1991;144:770-6.

24 Hoaken PCS. See reference 23: 1380-2.

25 Fontanarosa PB, Giorgio GT. Managing Jehovah's Witnesses: medical, legal, and ethical challenges. Annals of Emergency Medicine 1991;20:1148-9.

26 Anonymous [editorial]. Battery claim of Jehovah's Witness rejected by Michigan Court. Hospital Law Newsletter 1992;9:47.

27 Sacks DA, Koppes RH. Caring for the female Jehovah's Witness: balancing medicine, ethics, and the First Amendment. American Journal of Obstetrics and Gynecology 1994;170:452-5.

28 Anonymous [editorial]. Court says doctors were right to treat Jehovah's Witness. British Medical fournal 1992;305:272. The case was referred as $\operatorname{Re} T$ (adult: refusal of treatment) [1992] 4 All ER 649 (CA).

29 Brace JWA. Treating Jehovah's Witnesses. British Medical fournal 1992;305:588-9.

$30 \mathrm{~A}$ small brochure is being produced by the collaborating former JWs and internal reformers. At the time of writing, it is being printed. This brochure is also available and downloadable at the web page of the reformers' website: http:// www.visiworld.com/starter/newlight/abstain.htm. Availability of the printed version will be posted in this website. Additional useful information regarding biblical and historical aspects of the blood policy which may be used in discussion with JW patients is also downloadable from the same website.

31 Ridley DT. Jehovah's Witnesses and the refusal of blood. The Fournal of Clinical Ethics 1990;1:254-7.

32 Thomas JM. Jehovah's Witnesses and the transfusion debate: "We are not asking for the right to die". Canadian Medical Association fournal 1991;145:1559-60. 